\title{
Journal of Scheduling (2014)
}

\author{
E. Burke - M. Pinedo
}

Published online: 11 January 2014

(C) Springer Science+Business Media New York 2014

There have been various changes over the last couple of years in our journal. However, some things remain constant. We will always maintain an interdisciplinary focus as an international forum for scheduling research across disciplinary backgrounds and boundaries and we will always welcome all kinds of scheduling research from the theoretical to the practical. In addition, our emphasis has always been on excellence. In our view, these features lie at the very heart of the journal and they will not change as long as we remain editors.

One of the changes over the last couple of years has led us to publish 7-10 papers per issue on a regular basis. The reason for the increase in the number of papers is that we had to deal with a backlog of accepted papers that had become simply too much and that had to be reduced. Currently, we have reduced our backlog and we may want to go back to publishing say six papers per issue. The number of submissions is creeping up steadily and is now solidly over 200 articles per year; our target for the number of articles published annually is around 40 (in 6 issues). This implies an acceptance rate of approximately $20 \%$.

We have always welcomed the special issues of the journal and we remain open to suggestions for special issues that focus on specific scheduling topics or special issues that contain the very best papers presented at conferences. We work with our guest editors to ensure that the refereeing standards for the special issues are the same as for the regular issues. As

E. Burke $(\varangle)$

Deputy Principal for Research, University of Stirling, Stirling, UK e-mail: e.k.burke@stir.ac.uk

M. Pinedo

Department of Operations Research, Stern School of Business, New York, NY, USA

e-mail: mpinedo@stern.nyu.edu an example, in 2013 we had a special issue of selected papers from the Centre CNRS "La Villa Clythia" Frejus Workshop held in 2010. The very last issue of 2013 was a special issue dedicated to maintenance scheduling; this issue contains a very nice mixture of theoretical papers and applied papers. In addition to the special issues, we strongly encourage review papers of areas within scheduling that have been developed to such an extent that a survey paper would provide substantial benefits to the scheduling community at large.

We are pleased to report that our journal has continued to demonstrate success throughout 2013. According to eigenfactor.org, using its Article Influence score, the journal is ranked 20th out of 70 journals in the Operations Research and Management Science category. Our ranking in the SCImago Journal and Country Rank is 16th out of 86 journals in the category entitled, Management Science and Operations Research. This places us very comfortably in the top quartile of journals in this category. Our current Thompson Reuters impact factor is 0.941 and this places us in 40th position (from 79 journals) in the Operations Research and Management Science category. However, our 5-year impact factor is 1.737 and our position improves to 23rd if the 5-year impact factor is used to rank the journals. Moreover, it moves to 18 th if article influence is employed. From this brief analysis, it is clear that the journal ranks particularly well on article influence measures. Between January and September 2013, the number of article downloads was 25,506 (the figure for October-December was not available at the time of writing). This 9-month figure compares favorably against 28,431 for the whole of last year. During 2013, we have had (at the time of writing) 208 new submissions to the journal, with a few more weeks of the year to go.

Throughout 2013, the average time it has taken us to turn around an original submission (the time taken between submission and the first decision) has been 145 days, slightly 
less than 5 months but we are currently trying to put some gentle pressure on our Associate Editors and referees to bring the average turnaround time down even further. Although we are working hard to shorten our turnaround time, it is important to understand that many papers submitted to the Journal of Scheduling are very technical and thus require a longer refereeing time than some papers that are submitted to other journals.

As we said at the beginning of this editorial, there have been many changes since the journal first started 16 years ago. Over the years, many people have played a part in establishing the success of the journal and we are very grateful to all of them. Over the years, we have made many changes to our Editorial Board. Some Associate Editors step down and new Associate Editors start up. Our sincere thanks go to all our Associate Editors (old and new). Their efforts are of criti- cal importance to the success of the journal. Recently, our scheduling community lost one of its most prestigious members, Peter Brucker, through a tragic car accident. Peter had been an Associate Editor of our journal since its inception. He consistently set an example for everyone with his commitment to our field and to our journal. He will be missed dearly by the editorial team here at the Journal of Scheduling and by the scheduling community at large. A tribute to Peter appears in this issue of the journal. Last but not least, we are also very grateful to all the staff at Springer who make our job so much easier. Special thanks go to Matthew Amboy, Neil Levine, Sudha Subramanian (our Journal Editorial Office Assistant at Springer), and Supraja Yegnaraman (our Production Editor). Finally, we would like to thank our readers and authors for making the Journal of Scheduling as successful as it is. 